\title{
Physical and Biological Studies of Coal and Oil Fly Ash
}

\author{
by Gerald L. Fisher," Karen L. McNeill,* \\ Bruce A. Prentice* and Andrew R. McFarland ${ }^{\dagger}$
}

\begin{abstract}
Studies were performed to compare the physical and chemical characteristics and the in vitro macrophage cytotoxicity of oil and coal fly ash. Sampling methodology was developed to collect size-fractionated particulate matter from the smokestack of either a coal-fired or an oil-fired power plant. Morphological studies demonstrated particle heterogeneity, although most coal fly ash particles appeared to be spherical. Oil fly ash contained two major morphologies; nonopaque amorphous particles and opaque amorphous particles. Elemental analysis indicates that the coal ash is predominantly composed of aluminosilicate particles, while the oil ash is predominantly inorganic sulfates and carbonaceous particles. In vitro macrophage assays demonstrate that the finest coal fly ash particles are the most cytotoxic; the cytotoxicity is significantly less than that of $\alpha$-quartz, the positive control particle. In contrast, the oil fly ash particles are more cytotoxic than quartz. The cytotoxicity of oil fly ash is due to soluble components, possibly vanadium salts.
\end{abstract}

Associated with the generation of electricity by fossil fuel combustion is the production and subsequent environmental release of primary particulate matter. This material, fly ash, presently poses a major solid waste disposal problem and a potential health hazard. The ash from coal combustion is primarily aluminosilicate in matrix and contains surface layers of vapor-deposited inorganic and organic compounds. Furthermore, interparticle chemical variability is such that individual particle composition may be quite different than the average composition (1).

Although a number of studies have characterized the physical and chemical properties of coal fly ash (2), few detailed reports are available on oil fly ash. This is probably because of the relatively high ash content of coal and the large quantities combusted in power generation. It is estimated that 100 million tons of coal fly ash were produced in the United States in 1980 from combustion of coal averaging an ash content of $11 \%$ by mass (3). Particulate abatement technologies result in collection within the plant of $95-99 \%$ of the ash; thus $1-5 \%$ of the coal fly ash is released through the smokestack. Al-

\footnotetext{
*Battelle Columbus Laboratories, 505 King Avenue, Columbus, $\mathrm{OH} 43201$.

†Texas A\&M University, College Station, TX 77843.
}

though the ash content of oil used for electric power generation is two to three orders of magnitude less than the ash content of coal, most oil-fired power plants employ little or no particle emission technologies. Furthermore, oil-fired power plants are often located closer to urban centers than coal-fired plants. Thus, further efforts are required for characterization of fly ash from oil combustion.

In this report, collection techniques and physical and elemental analyses are presented for stack-collected, size-fractionated coal and oil fly ash samples. The in vitro cytotoxicity of these materials to bovine pulmonary macrophages is compared with the toxicity from exposure to $\alpha$-quartz (positive control) or glass beads (negative control.)

\section{Sample Collection}

The coal fly ash samples were collected directly from the stack of a power plant burning low sulfur, high ash western U.S. coal. The collection system has been described in detail by McFarland et al. (4). Salient features will be briefly reviewed here.

A sample probe was designed to enter the stack of the power plant downstream from the electrostatic precipitator (ESP). Thus, the particles collected were those which negotiated the particulate control device and would have been released to the environ- 
ment. Particles entering the sampling probe were drawn from the stack into an insulated, thermally regulated size classification system. The system was maintained at $95^{\circ} \mathrm{C}$ to avoid condensation of sulfuric acid. The classification consisted of two mechanical cyclone separators and a 25-jet centripeter (virtual, dichotomous impactor). Particles collected in the cyclones were maintained in stainless steel hoppers. The finest particles which penetrated the two cyclones were further aerodynamically classified into two fractions by the centripeter, with the resulting material depositing on fabric filters. The fabric filters were pulsed every 2 min with high velocity jets of cleaning air. The cleaning process was designed to avoid a significant pressure drop across the filter surface. Cleaning also avoided potential artifact formation associated with long-term, continuous exposure of collected fly ash to reactive stack gases. Samples were collected continuously over a 30-day period. The relatively long sampling period allowed collection of a sample representative of changes in fly ash composition that may result from variations in plant operating conditions.

The oil fly ash sampler was designed with thermal regulation similar to that employed for the coal fly ash samples (Fig. 1), but contained only one cyclone for size classification. Stack gas was drawn into the sampling module through a heated probe and passed into a cyclone. After the largest particles $(>2.5 \mu \mathrm{m})$ were collected by the cyclone the gas then flowed through a fabric filter, which was designed to collect the smaller particles. Subsequently, the gas was drawn through an orifice-type flowmeter and into a jet pump. Pressurized plant supply air (primary air) was used to drive the jet pump. The mixed stream of clean stack gas and expended primary air was discharged to the surrounding atmosphere.

Several operational variables were controlled or measured. Temperature level in the compartment was maintained at a preset value with $1.2 \mathrm{~kW}$ of electrical heat. A bead thermistor was used to sense temperature and its output was supplied to a solidstate controller. Pulse air for cleaning the fabric filter was supplied from bottled high pressure "zero" air. An electromechanical timer was used to set the pulse frequency and duration. Flow rate through the system was determined through the sensing of differential and static pressure levels at the orifice flowmeter and gas temperature. Flow through the

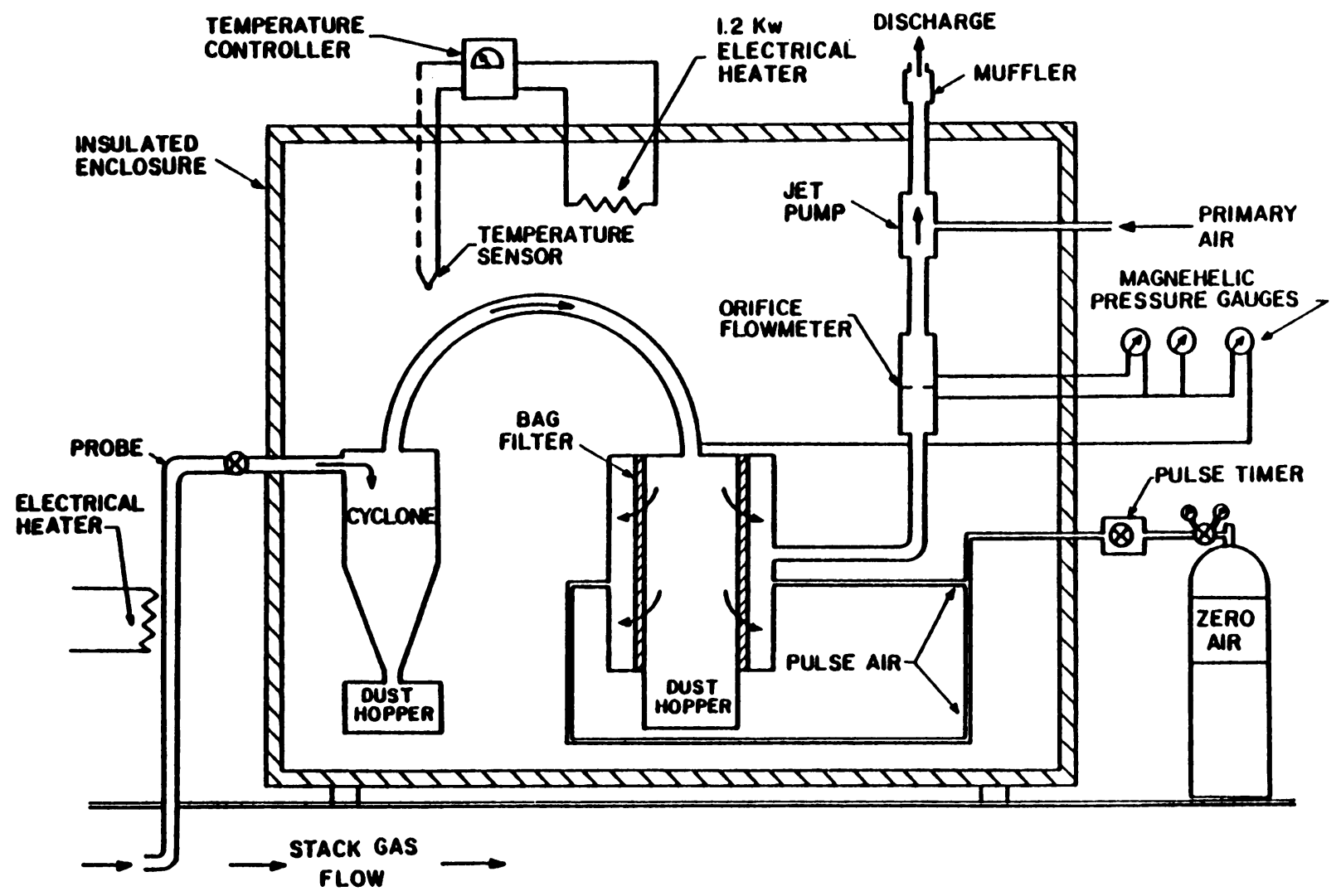

FIGURE 1. Stack sampler for collection of fly ash from an oil-fired power plant. 
system was set through an adjustment of the pressure level of primary air.

Laboratory calibrations indicated that the cutpoints of the sampling probe and the cyclone were 96 and $2.7 \mu \mathrm{m}$, respectively. Teflon felt was demonstrated to be a better medium than either Teflon fabric or Dacron fabric.

Oil fly ash samples were collected from a power plant burning Indonesian crude oil of low sulfur $(0.16 \%)$ and low ash $(<0.01 \%)$ content. Samples were collected over two consecutive 4 -day periods at a temperature of $140^{\circ} \mathrm{C}$; material from one sample period was used for chemical analysis and material from the second sample period for the remaining studies (5).

\section{Physical Properties}

\section{Particle Morphology}

In a previous report (6), the morphology and proposed morphogenesis of the coal fly ash particles were described. Light microscopic evaluation of the coal fly ash indicated a vast array of morphological forms and colorations. The relative abundances of eleven morphological classes were described: (a) amorphous, nonopaque particles; (b) amorphous, opaque particles; (c) amorphous, mixed opaque and nonopaque particles; (d) rounded, vesicular, nonopaque particles; (e) rounded, vesicular, mixed opaque and nonopaque particles; (f) angular, lacy, opaque particles; (g) cenospheres or hollow spheres; (h) plerospheres ( 7 ) or encapsulating spheres; (i) nonopaque solid spheres; (j) opaque spheres; and (k) spheres with either surface or internal crystals. A morphogenesis scheme was developed relating the 11 morphological classes to extent and duration of exposure to combustion zone temperatures and probable matrix composition. Opaque amorphous particles (b) and angular, lacy, opaque particles (f) were classified as unoxidized carbonaceous material or iron oxides. The opaque spheres (j) appeared to be predominantly magnetite and could be identified by magnetic separation. The amorphous (a) and rounded vesicular (d), nonopaque particles appeared to be aluminosilicate particles. Further heating of these particles may give rise to nonopaque spheres that are either solid (i), hollow (g), or packed with other particles (h). Similarly, the mixed opaque and nonopaque, amorphous (c) or rounded (e) classes may give rise to spherical particles upon increased exposure to combustion conditions in the boiler. The nonopaque, solid spheres ranged in color from water white to deep red. Crystals within glassy spheres $(k)$ are probably formed by heterogeneous nucleation within the molten silicate droplet.

The relative abundances of the 11 light-micro- scopically defined morphological classes in four sizeclassified, stack-collected coal fly ash fractions have been quantified. The four fractions had volume median diameters (VMD) of 2.2, 3.2, 6.3 and $20 \mu \mathrm{m}$ with associated geometric standard deviations $(\mathrm{og})$ of approximately 1.8. Only the nonopaque solid spheres increased in abundance with decreasing particle size; all other morphological classes appeared to increase in frequency with increasing particle size. Amorphous and vesicular particles (classes a, b, c, d, e and g) predominated in the coarsest fraction $(66 \%$ by number); while solid, nonopaque spheres predominated in the finest fraction ( $87 \%$ by number). The vast majority of amorphous and vesicular particles were cenospheres; plero spheres never exceed $0.5 \%$ in abundance.

Initial examination of dry samples of the oil fly ash illuminated by transmitted and reflected light showed the presence of very large particles, $30 \mu \mathrm{m}$, in both the fine (filter sample) and coarse (hopper sample) fractions. Because particles of this size could not have passed the cyclone, these observations indicated secondary particle growth took place on the filter either during or after collection. This hypothesis is supported by the morphologic appear. ance of the large particles. Examination under po larized light showed these particles to be eithes crystals or agglomerates of fine fly ash particles ce mented with a matrix of crystalline material. The large particles were not simply agglomerates 0 : smaller crystalline particles, but in many cases, ap peared to be single uninterrupted crystal grains Crystalline matrices of the cemented agglomerates were also seen to be continuous in many cases. From microscopic examination, it was not possible to determine the origin of the particles. Similarly, it was not possible to determine the effect of their presence or formation on particle morphology or size distributions. The particles may have been formed by condensation from the vapor phase, coagulation of droplets or reaction of vapors or droplets with particles on the filter surface. For this reason, morphologic and size evaluations were directed at characterization related to cell exposure in the macrophage studies.

Five major morphologic classes account for nearly all of the particles observed in both the coarse (hopper) and fine (filter) oil fractions: (A) nonopaque amorphous particles, predominantly waterwhite to pale yellow with little or no rounding; (B) opaque amorphous or lacy particles; (C) mixed opaque and nonopaque amorphous particles (apparently small agglomerates of classes $A$ and B); (D) nonopaque spheres; (E) opaque spheres. Nonopaque spheres were predominantly solid particles, with only a small percentage containing internal bubbles. 
These voids were, in nearly all cases, less than $10 \%$ of the particle volume. Colors for these spheres were generally water-white to pale yellow and only rarely dark orange or red. Nonopaque spheres predominated in the finer particles. Both size fractions showed trace amounts of several other morphologic classes, which because of their rarity, were not quantified. These include: very dark red or opaque acicular crystals, less than $0.3 \mu \mathrm{m}$ across and 10-20 $\mu \mathrm{m}$ long, often associated with water-white nonopaque amorphous particles having orange or red areas; nonopaque amorphous particles entirely or partially sky blue; nonopaque amorphous grey particles with relatively low index of refraction $\left(n_{D}\right.$ approximately 1.3-1.4); nonopaque amorphous particles in bright yellow.
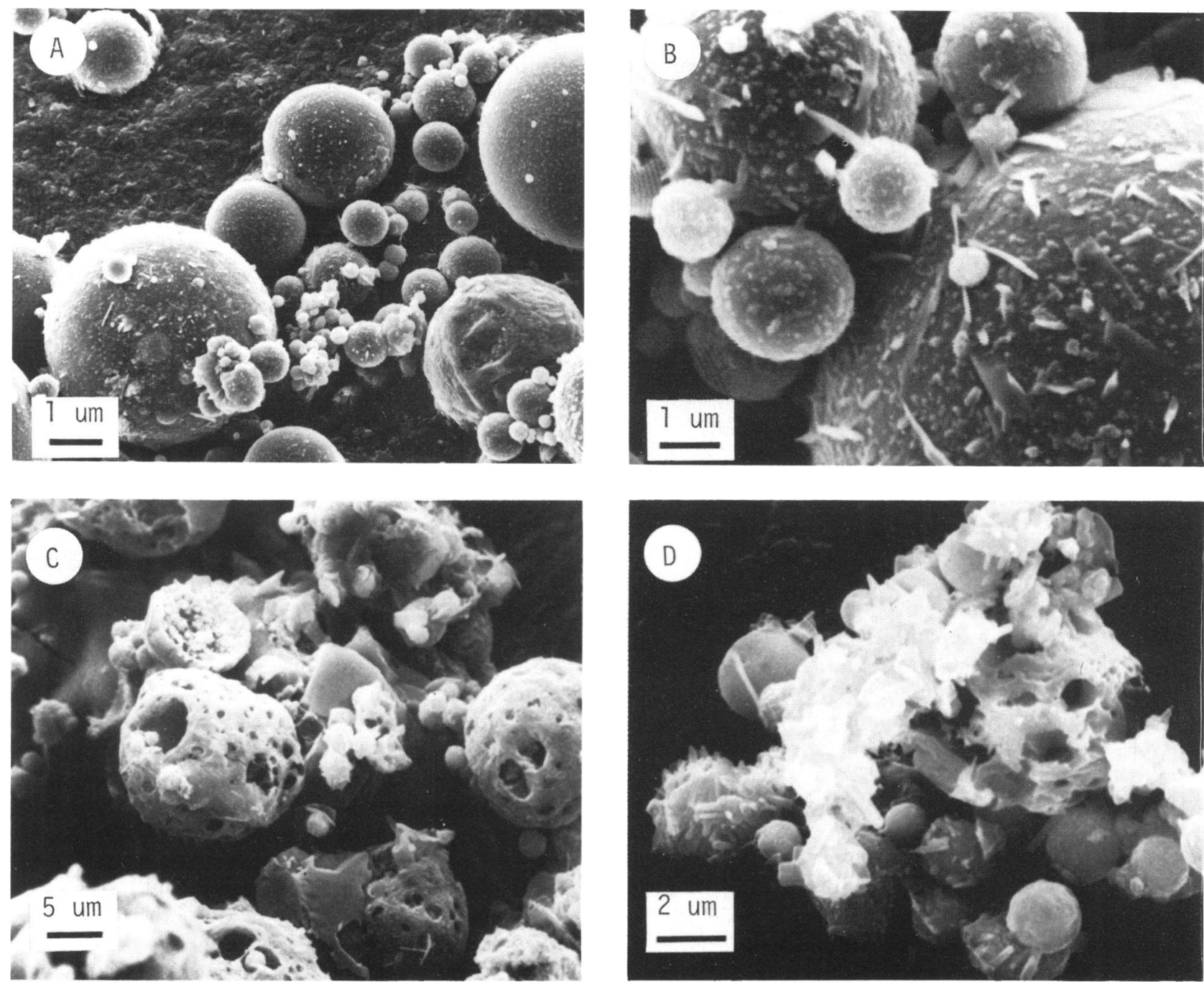

Figure 2. Scanning electron micrographs of coal $(A$ and $B)$ and oil $(C$ and $D)$ fly ash. Coal fly ash is typically spherical; surface crystal formation is often observed. Oil fly ash consists of spongy spherical and amorphous particles; crystals occur both on the surface of and separate from other particles. 
are predominantly spherical with surface features ranging from smooth to abundantly microcrystalline. Oil fly ash appears to be composed of two major types: (1) spongy, hollow spheres and amorphous particles and (2) irregular, solid particles.

\section{Size Distribution}

The size distributions of the four size-classified coal fly ash samples were determined by Coulter analysis (4). Fly ash was ultrasonically dispersed in a methanolic electrolyte solution. In contrast to the coal ash, the mass of collected oil fly ash was too small to allow Coulter analysis. Furthermore, the apparent crystal growth indicated the presence of soluble compounds. Thus, light microscopy was chosen for size analysis of the oil ash. Particles were sized by estimating the diameter of a sphere having the same projected area and comparing this to an eyepiece reticle, which was previously calibrated. All particles greater than $0.625 \mu \mathrm{m}$ were counted and tallied into one of six size classes, the last class contained particles greater than $6.25 \mu \mathrm{m}$. The upper class boundary of the largest size was set at $12.5 \mu \mathrm{m}$ because this was the diameter of the largest particle. The count distribution was converted to a volume distribution by assuming all particles were spheres and multiplying the count by the cube of the geometric mean of the class boundaries. The cumulative distribution of volume was calculated and fit to a lognormal distribution using the logarithm of the diameter and conversion of the volume distribution to a standard $\mathrm{z}$ function. After linearizing both parameters, a standard linear regression was performed.

The volume median diameters for the four coal fly ash samples were $2.2,3.2,6.3$ and $20 \mu \mathrm{m}$, with an associated geometric standard deviation $\left(o_{g}\right)$ of approximately 1.8 . Volume medium diameter (VMD) of the fine fraction of oil fly ash as determined from the regression was $5.6 \mu \mathrm{m}$, and the geometric standard deviation (og) was 2.3. Correlation coefficient $(r)$ for the fit was 0.9997. The coarse fraction of oil fly ash had a VMD of $8.9 \mu \mathrm{m}$, a $\sigma_{\mathrm{g}} 2.5$ and an $r$ of 0.9993 .

\section{Elemental Analysis}

Detailed elemental analyses by instrumental neutron activation analysis (INAA) (8) and atomic absorption spectroscopy (AAS) (9) have been performed for coal fly ash. With the exception of silicon, which appeared to decrease with decreasing particle size, the major element composition of the fractionated fly ash was relatively independent of particle size. Greater than $92 \%$ of the mass of the fractionated fly ash could be accounted for by ox- ides of $\mathrm{Si}, \mathrm{Al}, \mathrm{Fe}$ and $\mathrm{Ca}$. An enhancement factor was defined as the ratio of the element concentration in cut 4 (finest) to its concentration in cut 1 (coarsest). The more volatile elements (or their oxides), $\mathrm{Cd}, \mathrm{Zn}, \mathrm{Se}, \mathrm{As}, \mathrm{Sb}, \mathrm{Mo}, \mathrm{Ga}, \mathrm{Pb}$ and $\mathrm{V}$ displayed clear-cut increases in concentration with decreasing particle size, in agreement with the vaporcondensation mechanism of Natusch and Wallace (10). Thus, coal fly ash surfaces appear to serve as sites for condensation of vapor phase trace elements. It is noteworthy that such a vapor-phase condensation mechanism provides a surface concentration of the trace elements that may be considerably greater than either the matrix or average concentration.

The elemental concentrations of the fine and coarse oil fly ash samples were analyzed (5) by using methodology similar to that employed in analysis of the coal fly ash. In contrast to the coal ash, the majority of the inorganic components were present as sulfates. Sulfate anion accounted for $43 \%$ and $50 \%$ of the mass of the fine and coarse oil fly ash samples, respectively.

Elemental analyses of the coal fly ash sample with a size distribution similar to that of the fine oil fly ash sample are compared in Table 1 . The striking difference in matrix and trace elemental composition is apparent. In particular, while the oil ash is predominantly composed of a sulfate matrix, the coal ash is predominantly aluminosilicate. Of particular interest from a toxicological standpoint is the presence of high levels of nickel and vanadium in the oil ash compared to the coal ash. Furthermore, in agreement with the analytical findings (5), the metal sulfates are expected to be soluble in water or dilute acid.

\section{Bovine Macrophage Cytotoxicity}

To compare the cytotoxicity of the fly ash samples, in vitro exposure of the bovine pulmonary macrophage was used as a test system (11). Pulmonary alveolar macrophages (PAM) were harvested from the cardiac lung lobe of a healthy adult steer. The lung samples were obtained from a local slaughterhouse. The lobe was placed in a plastic bag and covered with crushed ice. Upon arrival at the laboratory (within $1 \mathrm{hr}$ of slaughter), a blunt 15-gauge needle was secured in the bronchi and the lobe was lavaged. Then $50-\mathrm{mL}$ aliquots of $2-4^{\circ} \mathrm{C} \mathrm{Ca-Mg-free}$ phosphate-buffered saline (PBS) were introduced into the lobe using a sterile 60 cc syringe until distention of the lobe. Lavage fluid was withdrawn and stored on ice in $250 \mathrm{~mL}$ sterile centrifuge tubes. A total of $500 \mathrm{~mL}$ of fluid was used for each lobe. Lavage fluid was centrifuged at $150 \mathrm{~g}$ for $30 \mathrm{~min}$. The 
Table 1. Elemental concentrations in coal and oil fly ash. ${ }^{a}$

\begin{tabular}{|c|c|c|c|c|c|}
\hline \multirow[b]{3}{*}{ Element } & \multirow[b]{3}{*}{ Technique $^{b}$} & \multicolumn{4}{|c|}{ Concentration } \\
\hline & & \multicolumn{2}{|c|}{$\begin{array}{c}\text { Coal } \\
(\mathrm{VMD}= \\
6.3 \mu \mathrm{m})\end{array}$} & \multirow{2}{*}{$\frac{\text { (VMD }}{\%}$} & \multirow{2}{*}{$\begin{array}{l}\text { Oil } \\
=5.6 \mu \mathrm{m}) \\
\frac{\mu \mathrm{g} / \mathrm{g}}{}\end{array}$} \\
\hline & & $\%$ & $\mu \mathrm{g} / \mathrm{g}$ & & \\
\hline$\overline{\mathrm{Si}}$ & AAS & 27.5 & & 0.9 & \\
\hline $\mathrm{Al}$ & AAS & 14.4 & & 0.4 & \\
\hline $\mathrm{Fe}$ & INAA & 2.9 & & 4.1 & \\
\hline $\mathrm{Ca}$ & AAS & 2.2 & & 1.2 & \\
\hline $\mathrm{Na}$ & AAS & 1.8 & & 3.7 & \\
\hline $\mathrm{K}$ & AAS & 0.8 & & 0.2 & \\
\hline $\mathrm{Ti}$ & AAS & 0.6 & & 0.02 & \\
\hline $\mathrm{Mg}$ & AAS & 0.5 & & 0.7 & \\
\hline $\mathrm{SO}_{4}=$ & IC & 0.8 & & 50 & \\
\hline $\mathrm{C}^{\mathrm{c}}$ & Insoluble residue & 0.2 & & $\sim 7$ & \\
\hline $\mathrm{Ni}$ & AAS & & 43 & & 103,000 \\
\hline V & INAA & & 244 & & 28,700 \\
\hline $\mathrm{Zn}$ & AAS & & 301 & & 3,040 \\
\hline Co & INAA & & 19 & & 3,160 \\
\hline $\mathrm{Se}$ & INAA & & 78 & & 5 \\
\hline As & INAA & & 87 & & 238 \\
\hline $\mathrm{Pb}$ & $\mathrm{AAS}$ & & 226 & & 426 \\
\hline $\mathrm{Cr}$ & AAS & & 66 & & 271 \\
\hline Mn & AAS & & 273 & & 357 \\
\hline $\mathrm{Be}$ & AAS & & 9 & & 7 \\
\hline $\mathrm{Th}$ & INAA & & 29 & & 51 \\
\hline $\mathbf{U}$ & INAA & & 22 & & 15 \\
\hline La & INAA & & 67 & & 80 \\
\hline Sc & INAA & & 16 & & 2 \\
\hline
\end{tabular}

${ }^{a}$ Coal fly ash data from Coles et al. (8) and Silberman and Fisher (9); oil fly ash data from Kimble et al. (5).

${ }^{\text {b AAS }}$ = atomic absorption spectroscopy; INAA = instrumental neutron activation analysis; $\mathrm{IC}=$ ion chromatography.

'Carbon contents estimated from insoluble coal fly ash fraction and from insoluble material from combined fine and coarse fly ash fractions.

supernatant was decanted, and the cells were resuspended and pooled using Minimum Essential Media (MEM; Gibco, Grand Island, NY). A 1:10 dilution of a portion of the cell pool with trypan blue was counted in a hemacytometer chamber to determine cell concentration and viability. Smears of the cell suspension were stained with Wright-Giemsa, and cellular differentials were determined. The specimen was discarded if it contained more than $10 \%$ neutrophils, lymphocytes and other contaminating cell types. Cells were suspended and then diluted to maintain appropriate test particle mass:cell ratios.

Pulmonary macrophages $\left(2 \times 10^{5}\right.$ viable cells $)$ were added to Leighton tubes containing complete media. The complete media was composed of $79 \%$ MEM, $1 \%$ antibiotic-antimycotic, $1 \% L$-glutamine and $20 \%$ heat-inactivated fetal bovine serum. Macrophages were attached to glass coverslips to obtain a homogeneous, adherent cell population. The cells were then exposed to control or test particles in the media and incubated for $20 \mathrm{hr}$. At the end of the incubation, viability was evaluated for two cov-
Table 2. Macrophage phagocytosis after exposure to fly ash, glass beads or silica.

\begin{tabular}{ccccc}
\hline & \multicolumn{4}{c}{ Phagocytosis at various doses, } \\
& \multicolumn{4}{c}{$\%$ of control } \\
\cline { 2 - 5 } & $\begin{array}{c}0.3 \\
\mathrm{mg} / \mathrm{mL}\end{array}$ & $\begin{array}{c}0.1 \\
\mathrm{mg} / \mathrm{mL}\end{array}$ & $\begin{array}{c}0.03 \\
\mathrm{mg} / \mathrm{mL}\end{array}$ & $\begin{array}{c}0.01 \\
\mathrm{mg} / \mathrm{mL}\end{array}$ \\
\hline Coal fly ash, VMD & & & & \\
Cut 1, $20 \mu \mathrm{m}$ & $54^{*}$ & $77^{*}$ & 88 & 94 \\
Cut 2, $6.3 \mu \mathrm{m}$ & $7^{*}$ & 98 & 101 & 98 \\
Cut 3, 3.2 $\mu \mathrm{m}$ & $58^{*}$ & $61^{*}$ & $85^{*}$ & $83^{*}$ \\
Cut 4, $2.2 \mu \mathrm{m}$ & $67^{*}$ & $77^{*}$ & $71^{*}$ & 89 \\
Oil fly ash, VMD & & & & \\
Coarse, $8.9 \mu \mathrm{m}$ & $0^{*}$ & $0^{*}$ & $40^{*}$ & $47^{*}$ \\
$\quad$ Fine, 5.6 $\mu \mathrm{m}$ & $2^{*}$ & $7^{*}$ & $44^{*}$ & $75^{*}$ \\
Positive control, VMD & & & & \\
$\quad$ Quartz, $2.0 \mu \mathrm{m}$ & - & $22^{*}$ & - & - \\
Negative control, VMD & & & & \\
Glass beads, 2.1 $\mu \mathrm{m}$ & $55^{*}$ & 87 & 94 & 100 \\
\hline
\end{tabular}

*Significantly different from control values, $p<0.05$.

erslips from each group, and cells were challenged with carbonized latex microspheres (20:1 particle to cell ratio) and reincubated for $30 \mathrm{~min}$. At the end of 30 min, coverslips were rinsed with PBS, air-dried, and stained with Wright-Giemsa. Coverslips were mounted on slides, and 200 cells per coverslip (50/ quadrant) were scored for phagocytic uptake of the inert microspheres.

Results of the cytotoxicity assays are presented in Table 2. Test particle concentrations were $0.3,0.1$, 0.03 and $0.01 \mathrm{mg} / \mathrm{mL}$ for all test substances except quartz. Based on previous studied (unpublished data), quartz was used as a positive control at one concentration, $0.1 \mathrm{mg} / \mathrm{mL}$.

The phagocytic activity (Table 2) of the macrophages was significantly inhibited $(p<0.001)$ at the $0.3 \mathrm{mg} / \mathrm{mL}$ dose with the negative control particles (glass beads). Similar inhibition of phagocytosis was observed with all other materials tested at this concentration. The $3.2 \mu \mathrm{m}$ fraction of coal fly ash depressed phagocytic function at all four dose levels, in contrast to the other fractions of coal ash. The coal fly ash fractions with the largest particle size (cuts 1 and 2) had little effect compared to the positive control which reduced phagocytosis to $22 \%$ of control values at the dose tested $(0.1 \mathrm{mg} / \mathrm{mL})$. The sample of coarse- $(8.9 \mu \mathrm{m})$ oil fly ash had significant effects on phagocytosis at all concentrations $(p<0.001)$. Phagocytosis was again significantly depressed for all doses of fine oil fly ash $(5.6 \mu \mathrm{m})$, but the lowest dose of fine oil fly ash did not depress phagocytosis to as great a degree as the coarse sample.

Subsequent studies were performed to identify the cytotoxic components of the oil ash. Fine oil ash and, as a control, glass beads were incubated in media for $20 \mathrm{hr}$, and a portion of the oil fly ash parti- 
cles was sequentially incubated in media for a second 20 -hr incubation. The soluble and particulate fractions were tested in order to evaluate the relative contributions of each component to the biological activity observed with the parent material.

The soluble fraction of glass beads had no effect on phagocytosis at any dose level. The particulate fraction of glass beads significantly $(p<0.01)$ depressed phagocytosis only at the $0.3 \mathrm{mg} / \mathrm{mL}$ dose, but all lower doses were unaffected. Both the soluble and particulate fine oil fly ash fractions inhibited phagocytosis after the first 20 -hr incubation. The particulate fraction reduced phagocytosis significantly $(p<0.01)$ in all but the lowest dose. The soluble oil fly ash significantly depressed phagocytosis $(p<0.001)$ only in the two higher concentrations.

Only the soluble fraction of oil fly ash remained cytotoxic after a second sequential incubation of the fly ash particles in media. The second soluble fraction depressed phagocytosis $(p<0.001)$ at the two higher concentrations. The particulate fraction depressed phagocytosis only at the highest dose level, similar to the particulate response observed with glass beads. The second extraction resulted in oil fly ash particles that were less inhibitory of phagocytosis than either the parent material or particles which were extracted one time.

Elemental analyses of $\mathrm{Ni}$ and $\mathrm{V}$ in the two soluble fractions of oil fly ash $(3 \mathrm{mg} / \mathrm{mL})$ were performed by atomic absorption spectroscopy. The nickel and vanadium concentrations in the first soluble fraction were 267 and $20 \mu \mathrm{g} / \mathrm{mL}$, respectively; the second soluble fraction contained $13 \mu \mathrm{g} / \mathrm{mL}$ of nickel and 17 $\mu \mathrm{g} / \mathrm{mL}$ of vanadium. In contrast to the oil fly ash, previous studies of the finest coal fly ash sample (12) indicated dissolution of no detectable $\mathrm{V}$ or $\mathrm{Ni}$ after shaking $0.5 \mathrm{~g}$ samples in $50 \mathrm{~mL}$ water at room temperature for $24 \mathrm{hr}$, i.e., solution concentrations of less than 0.02 and $0.2 \mu \mathrm{g} / \mathrm{mL}$ for $\mathrm{V}$ and $\mathrm{Ni}$, respectively. On the basis of other studies performed in our laboratory (unpublished data), it appears that the biological activity of the oil fly ash is due to the presence of soluble forms of vanadium.

\section{Summary and Conclusions}

Marked differences were observed in the physical and chemical properties of coal and oil fly ash. Light microscopic analysis of coal fly ash resulted in the development of a morphogenesis scheme containing 11 particle morphologies. In contrast, to the coal fly ash, only five morphological types of particles were identified in the oil fly ash. This difference may, in part, represent differences in particle morphogenesis. While most of the coal fly ash particles result from the heating of accessory aluminosilicate min- eral associated with the organic phase of the coal, the oil fly ash appears to primarily contain sulfates and carbonaceous particles. The heterogeneity of fly ash morphologies not only reflects the mechanism of formation of the particle, but also its chemical composition.

Indeed, such heterogeneity in particulate composition has led Hayes et al. (13) to propose a model for exposure of individual lung cells to trace elements in fly ash. This model points out that segregation of elements in individual particles results in higher intracellular levels within individual phagocytizing cells. Furthermore, the particle may be directly toxic or a source of diffusable ions or molecules which may lyse the phagocytizing cell and hence be available for phagocytosis by another cell. In this manner, an individual particle may be cytotoxic to a population of cells. This hypothesis has been verified in studies with nickel subsulfide particles (14). These studies demonstrated increased cytotoxicity to bovine macrophages of nickel subsulfide particles compared to solubilized nickel subsulfide or soluble nickel chloride.

Elemental analyses further emphasize the differences between coal and oil fly ash. The aluminosilicate matrix of coal fly ash is quite different than the sulfate and carbonaceous matrices of the oil ash. Of greater biological significance are the high nickel and vanadium concentrations. Furthermore, based on the solubility of these elements, it is likely that they are present as sulfates. It is also interesting to note the relatively high concentrations of zinc and cobalt in the oil ash samples. Trace elements such as $\mathrm{K}, \mathrm{Ti}$, and $\mathrm{Sc}$ - which are generally thought to be associated with accessory minerals - are present at somewhat higher concentrations in the coal fly ash.

Studies of the cytotoxicity of coal and oil fly ash were performed after in vitro exposures of bovine pulmonary alveolar macrophages. Although the finest fly ash fractions were the most inhibitory of phagocytosis, the toxicity of coal fly ash was rather low compared to that of $\alpha$-quartz or oil fly ash. The high cytotoxicity of the oil ash was associated with a soluble component, probably a vanadium salt.

In summary, these studies demonstrate marked differences in the physical and chemical properties of coal and oil fly ash. Furthermore, it appears that these differences also account for differential cytotoxicity of oil and coal fly ash.

The authors gratefully acknowledge the technical assistance of Charles Democko (Battelle) and the electron micrographs of Gregory Finch (Donner Laboratory, University of California, Berkeley). This work was supported by the California Air Resources Board and the Electric Power Research Institute (Contract RP 1639-2). 


\section{REFERENCES}

1. Pawley, J. B., and Fisher, G. L. Using simultaneous three color X-ray mapping and digital-scan-stop for rapid elemental characterization of coal combustion by-products. J. Microsc. 110: 87-101 (1977).

2. Fisher, G. L., and Natusch, D. F. S. Size-dependence of the physical and chemical properties of fly ash. In: Analytical Methods for Coal and Coal Products, III (C. Karr, Ed.), Academic Press, New York, 1979, pp. 489-541.

3. Fisher, G. L., Chrisp, C. E., and Raabe, O. G. Physical factors affecting the mutagenicity of fly ash from a coal-fired power plant. Science 205: 879-881 (1979).

4. McFarland, A. R., and Russell, D. C. Design and calibration of a stack sampler for oil fly ash. Texas A\&M Air Quality Laboratory Publication 4126/01/07/81/ARM (1981).

5. Kimble, B. J., Raabe, O. G., Wei, C., and Silberman, D. Toxicological investigation of fine particle emissions from oil-fired power plants. State of California Air Resources Board, final report (1981).

6. Fisher, G. L., Prentice, B. A., Silberman, D., Ondov, J. M., Bierman, A. H., Ragaini, R. C., and McFarland, A. R. Physical and morphological studies of size-classified coal fly ash. Environ. Sci. Technol. 12: 447-451 (1978).

7. Fisher, G. L., Chang, D. P. Y., and Brummer, M. Fly ash collected from electrostatic precipitators: microcrystalline structures and the mystery of the spheres. Science 192: 553-557 (1976).

8. Coles, D. G., Ragaini, R. C., Ondov, J. M., Fisher, G. L., Silberman, D., and Prentice, B. A. Chemical studies of stack fly ash from a coal-fired power plant. Environ. Sci. Technol. 13: 455-459 (1979).

9. Silberman, D., and Fisher, G. L. Room temperature dissolution of coal fly ash for trace metal analysis by atomic absorption spectrometry. Anal. Chim. Acta 106: 299-307 (1979).

10. Natusch, D. F. S., Wallace, J. R., and Evans, C. A. Toxic trace elements preferential concentration in respirable particles. Science 183: 202-204 (1974).

11. Fisher, G. L., McNeill, K., and Democko, C. J. Application of bovine macrophage bioassays in the analysis of toxic agents in complex environmental mixtures. In: Symposium on Application of Short-term Bioassays in the Analysis of Complex Environmental Mixtures (M. Waters, S. Sandhu, J. Lewtas, L. Claxton, W. Chernoff and S. Nesnow, Eds.), Plenum Press, New York, 1983, pp. 257-268.

12. Hansen, L. D., and Fisher, G. L. Elemental distribution in coal fly ash particles. Environ. Sci. Technol. 14: 1111-1117 (1980).

13. Hayes, T. L., Pawley, J. B., Fisher, G. L., and Goldman, M. A toxicological model of fly ash exposure to lung cells. Environ. Res. 22: 499-509 (1980).

14. Fisher, G. L., Chrisp, C. E., McNeill, K. L., McNeill, D. A., Democko, C., and Finch, G. L. Mechanistic evaluation of the pulmonary toxicology of nickel subsulfide. In: Symposium on the Toxicology of Petroleum Hydrocarbons ( $H$. MacFarland, C. Holdsworth, R. Call, and M. Kane, Eds.), American Petroleum Institute, Washington, DC, 1982, pp. 87-96. 